\title{
Perforator Flaps after Excision of Large Epidermal Cysts in the Buttocks
}

\author{
Sang Wha Kim ${ }^{1}$, Seong Hyeok Yang ${ }^{2}$, Jeong Tae Kim², Youn Hwan Kim² \\ ${ }^{1}$ Department of Plastic and Reconstructive Surgery, The Catholic University of Korea College of Medicine, Seoul; ${ }^{2}$ Department of Plastic and \\ Reconstructive Surgery, Hanyang University College of Medicine, Seoul, Korea
}

Background Epidermal cysts are commonly occurring masses usually less than $5 \mathrm{~cm}$ in diameter, but in predisposed patients, epidermal cysts can grow relatively large due to chronic infection.

Methods From June 2002 to July 2010, 17 patients received 19 regional perforator-based island flaps to cover defects due to the excision of large epidermal cysts (diameter $>5 \mathrm{~cm}$ ) in the buttocks. Eight patients had diabetes, and seven had rheumatoid arthritis. The pedicles were not fully isolated to prevent spasms or twisting.

Results All the flaps survived completely, except for one case with partial necrosis of the flap, which necessitated another perforator-based island flap for coverage. There were two cases of wound dehiscence, which were re-closed after meticulous debridement. There were no recurrences of the masses during follow-up periods of 8.1 months (range, 6-12 months).

Conclusions In patients with large epidermal cysts and underlying medical disorders, regional perforator-based island flaps can be the solution to coverage of the defects after excision.

Keywords Epidermal cyst / Perforator flap / Surgical flaps
Correspondence: Youn Hwan Kim Department of Plastic and Reconstructive Surgery, Hanyang University College of Medicine, 222 Wangsimni-ro, Seongdong-gu, Seoul 133-791, Korea Tel: +82-2-2290-8560 Fax: +82-2-2295-7671 E-mail:younhwank@daum.net

No potential conflict of interest relevant to this article was reported.

Received: 13 Jun 2013 • Revised: 22 Jul 2013 • Accepted: 5 Aug 2013

pISSN: 2234-6163 • elSSN: 2234-6171 • http://dx.doi.org/10.5999/aps.2014.41.2.140 • Arch Plast Surg 2014;41:140-147

\section{INTRODUCTION}

Epidermal cysts are the most common benign masses of the skin; they grow slowly and usually reach up to 1 to $5 \mathrm{~cm}$ in diameter [1-3]. The differential diagnosis of cystic lesions includes neurogenic or other tumors with cystic degeneration and hemorrhage, lymphangioma with hemorrhage, cystic teratoma, large ganglion cyst, and echinococcal cyst. Therefore, imaging studies are indispensable for the diagnosis of exact size and nature of the cyst, and computed tomography, ultrasonography, and magnetic resonance imaging are very useful for diagnosing an epidermal cyst $[2,3]$.

These benign masses fluctuate in size when infected, and even though they may subside spontaneously, the affected patients can feel discomfort, and the symptoms can interfere with the patients' social life if they are not treated quickly. Recommended treatment modalities vary, from laser marsupialization to simple excision, but there are no clear guidelines regarding the treatment of choice [4-8].

Treatment results are considerably good with small epidermal cysts, with easily achieved primary closure after surgical excision. However, there are several reports of epidermal cysts larger than $5 \mathrm{~cm}$ in diameter in the gluteal region [1-3]. Moreover, infected epidermal cysts can make meticulous excision more difficult and may necessitate the removal of the surrounding tissue to prevent recurrence and to control the infection. Hence, epidermal cysts in this region can result in large defects of the buttock after excision. Primary closure of these defects can lead to hematomas 
and longstanding postoperative seromas due to the dead spaces, and high tension in closure can increase the incidence of wound dehiscence.

To prevent the abovementioned complications, we cover these defects with perforator-based island flaps (PBIFs) to avoid primary closure with high tension. We describe below our flap design and our experience of using this flap to cover post-excisional defects caused by large epidermal cysts in the gluteal region.

\section{METHODS}

We reviewed the electronic charts of 23 patients who underwent excision of epidermal cysts in the gluteal region between June 2002 and July 2010. Four cases of epidermal cysts with a diameter of less than $5 \mathrm{~cm}$, and two cases of primary closure of defects after the excision of epidermal cysts with a diameter of more than $5 \mathrm{~cm}$, were excluded. Hence, we considered 17 patients who received 19 regional PBIFs for coverage of post-excision defects from large epidermal cysts.

Defect sizes after excision with debridement ranged from 4 $\mathrm{cm} \times 2.5 \mathrm{~cm}$ to $14.5 \mathrm{~cm} \times 7 \mathrm{~cm}$, and flap dimensions ranged from $8 \mathrm{~cm} \times 5 \mathrm{~cm}$ to $15 \mathrm{~cm} \times 7.5 \mathrm{~cm}$. One patient underwent reconstruction of two regions after excision of two epidermal cysts, and she received three PBIFs due to partial necrosis of one of the flaps. Detailed patient histories and flap information are given in Table 1.

\section{Surgical technique and refinements}

Under general anesthesia, patients were placed in the prone position. In all cases, the epidermal cysts showed some degree of infection, and there was severe adhesion of the cysts to the surrounding tissue. Excision of the cystic mass as well as radical debridement of the surrounding infected tissue was performed (Fig. 1A). A Doppler probe was used for locating the perforator around the defect (Fig. 1B).

The gluteal regions have numerous perforators, and it is relatively easy to find suitable perforators. The perforator located closest to the defect should be selected, and the border of the flap should be designed to be adjacent to the defect, with the long axis typically having an angle of $60^{\circ}$ to $120^{\circ}$ to the long axis of the defect (Fig. 1C). After debridement, the cavity often has a round shape due to the cystic characteristics of epidermal inclusion cysts. However, closure of the donor site and rotation of the flap affect the shape and size of the final defect, which typically changes from round to oval. This change necessitates the surgeon to base his/her calculations on the expectation that

\section{Table 1. Detailed patient information}

\begin{tabular}{|c|c|c|c|c|c|c|c|c|c|c|}
\hline No. & $\begin{array}{l}\text { Sex/Age } \\
\text { (yr) }\end{array}$ & $\begin{array}{l}\text { Duration of } \\
\text { disease (yr) }\end{array}$ & $\begin{array}{l}\text { Associated } \\
\text { disease }\end{array}$ & $\begin{array}{l}\text { Previous } \\
\text { history }\end{array}$ & $\begin{array}{l}\text { Location } \\
\text { of defect }\end{array}$ & $\begin{array}{l}\text { Diameter } \\
\text { of cyst }(\mathrm{cm})\end{array}$ & $\begin{array}{l}\text { Size of de- } \\
\text { fect }\left(\mathrm{cm}^{2}\right)\end{array}$ & $\begin{array}{l}\text { Flap dimen- } \\
\text { sion }\left(\mathrm{cm}^{2}\right)\end{array}$ & Complications & $\begin{array}{l}\text { Follow- } \\
\text { up (mo) }\end{array}$ \\
\hline 1 & $\mathrm{M} / 70$ & 12 & Diabetes & I\&D & Ischium & 6 & $6 \times 8$ & $8 \times 5$ & None & 8 \\
\hline 2 & $M / 56$ & 23.5 & $\begin{array}{l}\text { Pharyngeal cancer } \\
\text { Chemotherapy }\end{array}$ & None & Ischium & 6.5 & $7 \times 9$ & $9 \times 6$ & None & 6 \\
\hline $3^{\text {a) }}$ & $\mathrm{F} / 50$ & 20 & Rheumatoid arthritis & $\begin{array}{l}\text { Sclerosing agent } \\
\text { injection }\end{array}$ & Coccyx & 7.5 & $8 \times 8$ & $15 \times 6$ & $\begin{array}{l}\text { Partial loss } \\
\text { (PBIF coverage) }\end{array}$ & 8 \\
\hline $4^{a)}$ & $\mathrm{F} / 50$ & 20 & Rheumatoid arthritis & None & Ischium & 5.5 & $7 \times 8$ & $7 \times 3$ & None & 8 \\
\hline 5 & $\mathrm{~F} / 62$ & 7 & Rheumatoid arthritis & I\&D & Coccyx & 6 & $5 \times 6$ & $14 \times 7$ & None & 6 \\
\hline 6 & $M / 53$ & 3 & Diabetes & Simple excision & Coccyx & 5.5 & $5 \times 7$ & $12 \times 7.5$ & None & 9 \\
\hline 7 & $\mathrm{M} / 78$ & 12 & ASO Diabetes & None & Coccyx & 7 & $8 \times 9$ & $14 \times 8$ & $\begin{array}{r}\text { Wound dehiscence } \\
\text { (primary closure) }\end{array}$ & 7 \\
\hline 8 & $\mathrm{~F} / 55$ & 4 & Rheumatoid arthritis & None & Coccyx & 8 & $7 \times 14.5$ & $15 \times 7$ & None & 11 \\
\hline \multirow[t]{2}{*}{9} & $\mathrm{~F} / 72$ & 2.5 & Rheumatoid arthritis & I\&D & Coccyx & 6.5 & $5 \times 7$ & $13 \times 7$ & None & 6.5 \\
\hline & & & Congestive heart failure & & & & & & & \\
\hline 10 & $\mathrm{M} / 77$ & 11 & Diabetes & $I \& D$ & Ischium & 5 & $2.5 \times 4$ & $9 \times 4$ & None & 6 \\
\hline 11 & $M / 38$ & 1.5 & None & $1 \& D$ & Coccyx & 7 & $5 \times 7$ & $13 \times 7$ & None & 7 \\
\hline 12 & $\mathrm{~F} / 45$ & 8 & Rheumatoid arthritis & None & Coccyx & 5.5 & $5 \times 6$ & $11 \times 7$ & None & 12 \\
\hline 13 & $M / 63$ & 7 & Diabetes & None & Coccyx & 6 & $6 \times 6$ & $11 \times 6$ & None & 8 \\
\hline 14 & $\mathrm{~F} / 62$ & 10 & $\begin{array}{l}\text { Diabetes } \\
\text { Chronic renal failure }\end{array}$ & None & Coccyx & 7 & $6 \times 7$ & $12 \times 7$ & $\begin{array}{r}\text { Wound dehiscence } \\
\text { (primary closure) }\end{array}$ & 6 \\
\hline 15 & $M / 68$ & 4 & Diabetes & None & Ischium & 5.5 & $4 \times 4$ & $10 \times 6$ & None & 8 \\
\hline 16 & $M / 35$ & 2.5 & None & I\&D & Coccyx & 6 & $4 \times 5$ & $14 \times 7$ & None & 10 \\
\hline 17 & $\mathrm{~F} / 72$ & 7 & Rheumatoid arthritis & $\begin{array}{l}\text { Sclerosing agent } \\
\text { injection }\end{array}$ & Coccyx & 6.5 & $4 \times 6$ & $12 \times 7$ & None & 9 \\
\hline 18 & F/66 & 5 & Diabetes & None & Ischium & 6 & $5 \times 7$ & $11 \times 6$ & None & 10 \\
\hline
\end{tabular}




\section{Fig. 1. Perforator-based island flap}

(A) A female with a coccygeal mass. A 62-year-old female with a coccygeal mass present for 7 years. (B) Perforators are mapped using a Doppler. A line connecting the posterior superior iliac spine (PSIS) and coccyx is drawn. Perforators along this line are mapped using a portable Doppler. (C) The design of the flap. The flap is designed with the long axis at an acute angle to the defect. When the donor site is closed, the defect becomes elongated, which requires the flap design to be longer and narrower than the original defect. (D) The flap is elevated disto-proximally. The flap is elevated disto-proximally, but the pedicle is not fully isolated. Thus, there is less spasm and torsion of the pedicles. (E) Inset of the flap without tension. The flap is inset on the defect without tension. The pedicle is dissected only until a sufficient arc of rotation is achieved. (F) The flap is placed after sutures. Negative suction drains are inserted. The T-junction is sutured first.
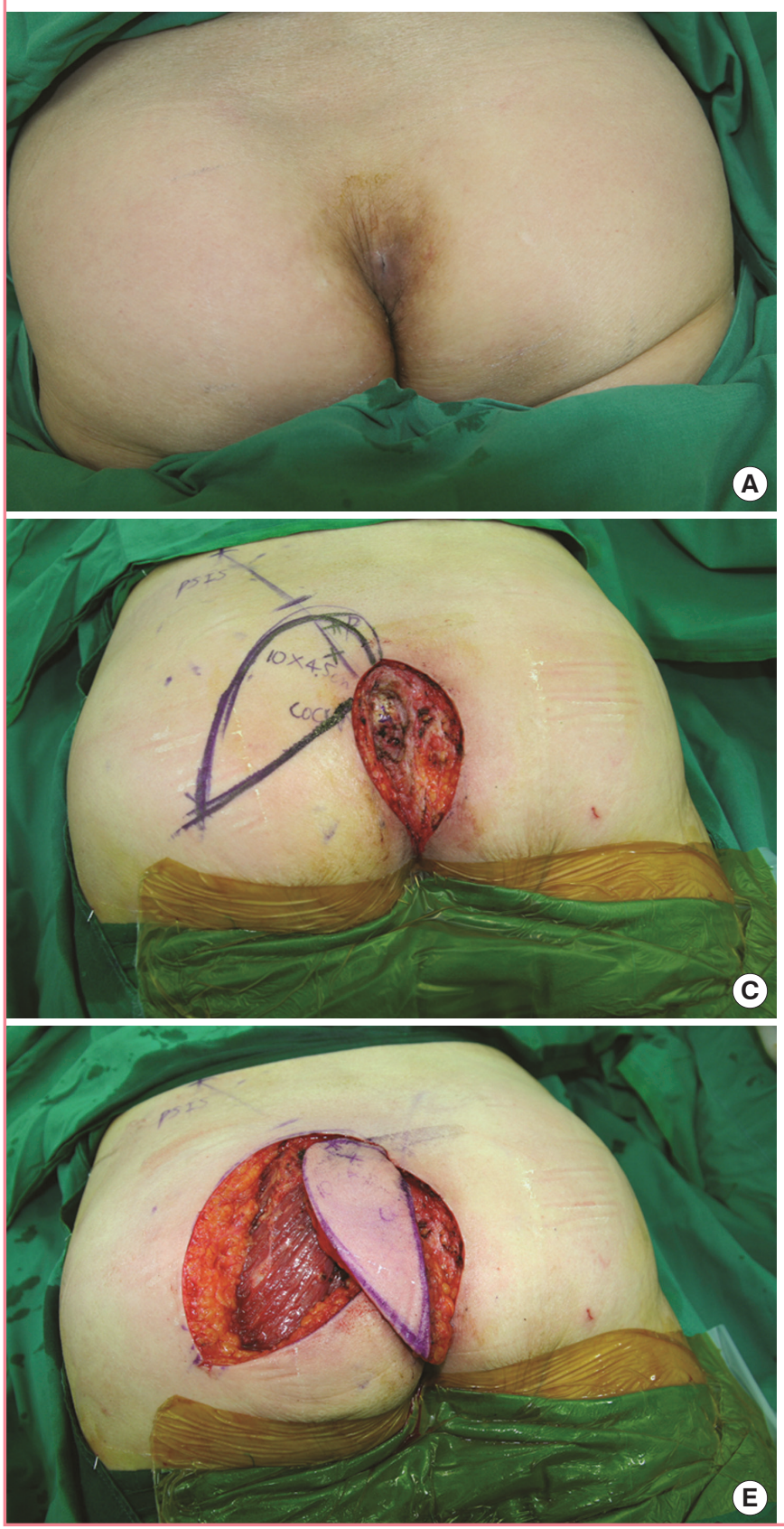

the width of the initial defect will be diminished and its length increased.

Primary closure without tension on the donor site is very important in reconstruction, even for large defects. An elliptically shaped flap is particularly suitable for directly closing the donor
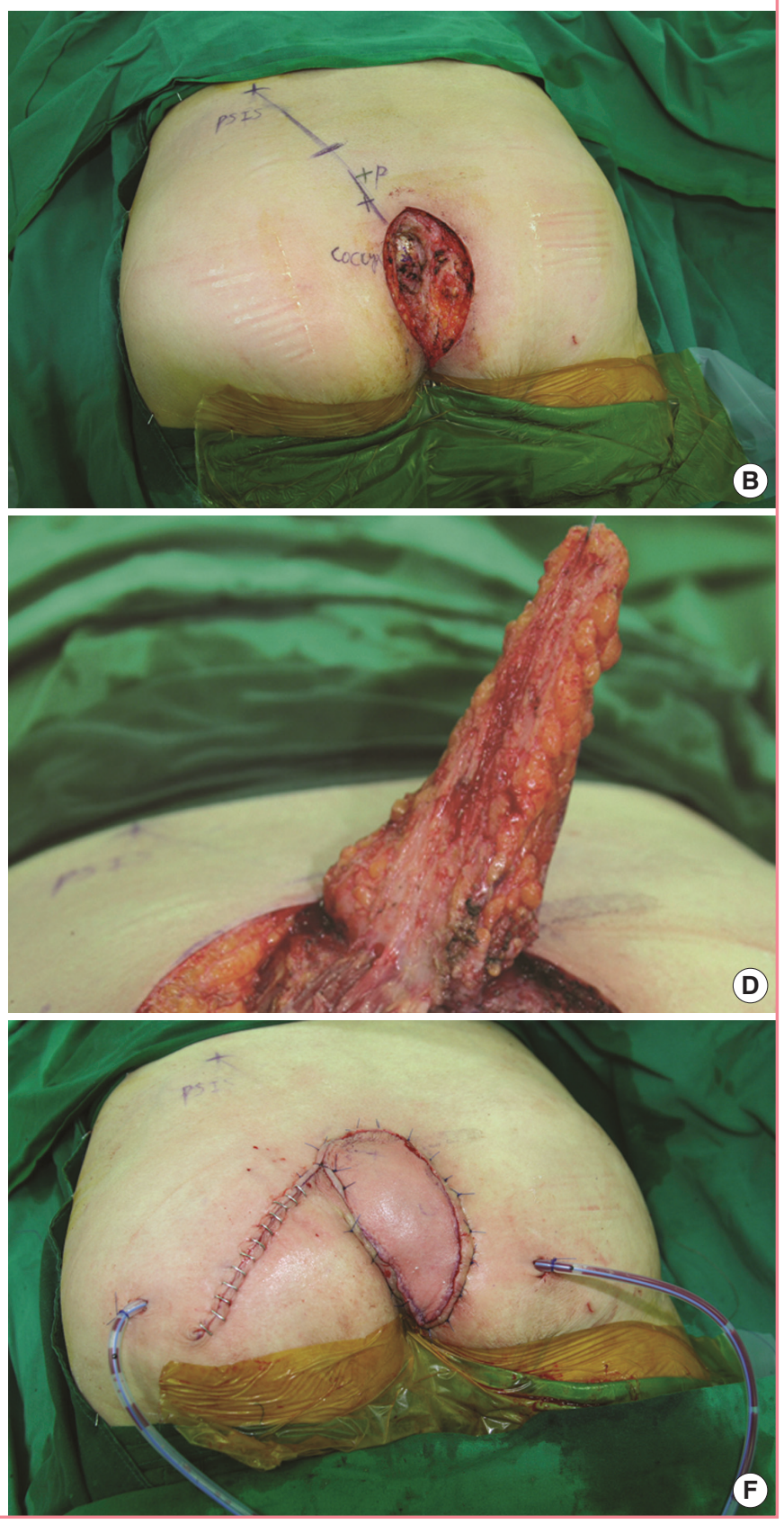

site and fitting the flap onto the defect. The flap is elevated distoproximally at the suprafascial level until a sufficient rotation arc to cover the defect is achieved. Great care must be taken when dissecting near the perforator. However, there is no need to meticulously dissect around the perforators to skeletonize them 


\section{Fig. 2. Perforator-based island flap}

(A) Masses on the coccyx and right ischium. A 50-year-old female was referred to our department for masses on her coccyx and right ischium, which had enlarged over 20 years. The area of the larger mass was $13 \mathrm{~cm} \times 8 \mathrm{~cm}$, and that of the smaller mass was $7 \mathrm{~cm} \times 6.5 \mathrm{~cm}$. (B) Computed tomography scan of the mass. The computed tomography scan revealed a $13 \mathrm{~cm} \times 8 \mathrm{~cm}$ mass on the coccyx. (C) The design of the flap. The flap design is shown after complete excision of the cyst. Note that the flap is narrower and longer than the defect. These dimensions can be calculated approximately by pinching the donor site to simulate closure and measuring the defect. (D) Immediately after the flap inset. Three negative drains were placed: two for the larger flap, and one for the smaller flap. (E) A microscopic view of the epidermal cyst. The cyst wall is relatively well-circumscribed with a keratin filling inside the cyst $(H \& E, \times 100)$. (F) View of the flaps after 8 months. There were no other complications or loss of flaps after one revision.
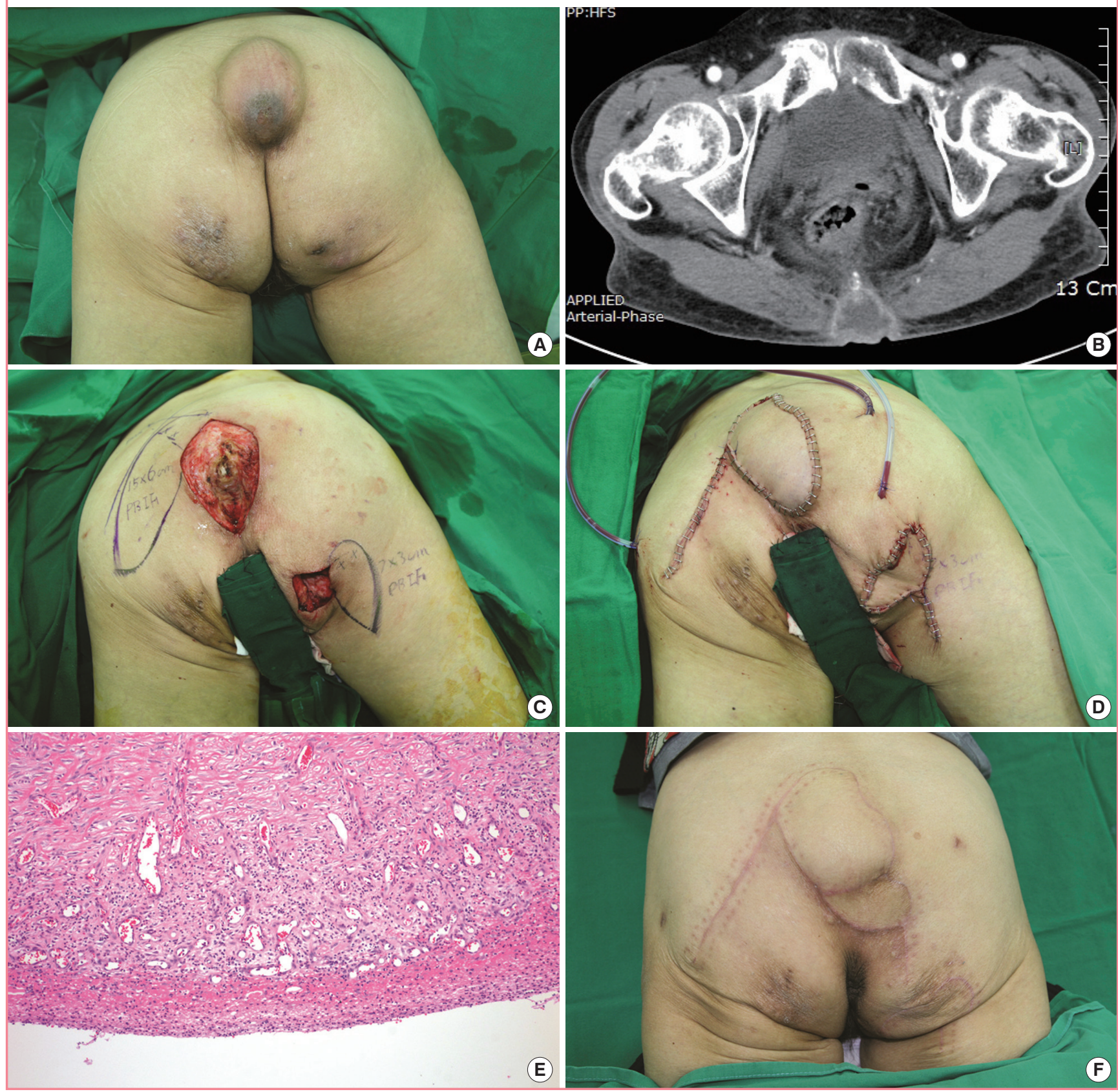

(Fig. 1D). Dissection is performed until a sufficient arc of rotation is achieved without full isolation of the pedicle (Fig. 1E). After flap elevation and before flap insertion, the pivot point (T-junction area) is closed without tension. After suturing the pivot point, the remaining donor site can be closed without ten- sion (Fig. 1F). In some cases with large dead spaces, the flaps were tailored and de-epithelized after T-junction closure. Negative suction drainages were positioned at the donor site and the flap site, and light dressings were applied. To prevent contamination of the wound by fecal material, Dermabond (Ethicon, San 


\section{Fig. 3. Perforator-based island flap}

(A) The defect after excision of the cyst. Although the skin defect measured $2.5 \mathrm{~cm} \times 4 \mathrm{~cm}$, the pocket inside measured almost 6 $\mathrm{cm} \times 5.5 \mathrm{~cm}$. (B) A microscopic view of the epidermal cyst. The cyst wall is relatively well-circumscribed with a keratin filling inside the cyst $\left(H \& E_{1} \times 100\right)$. (C) The flap after 9 months. There were no postoperative complications, and the flap survived completely.

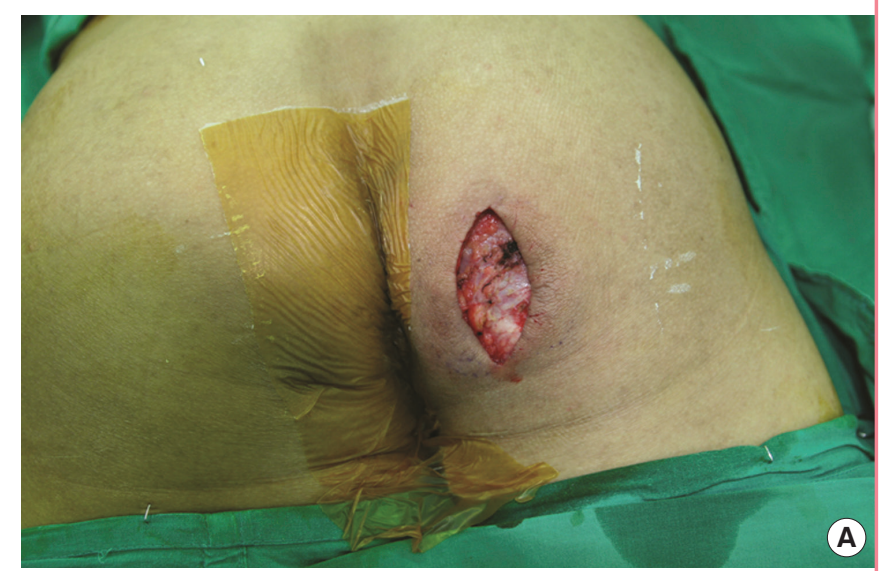

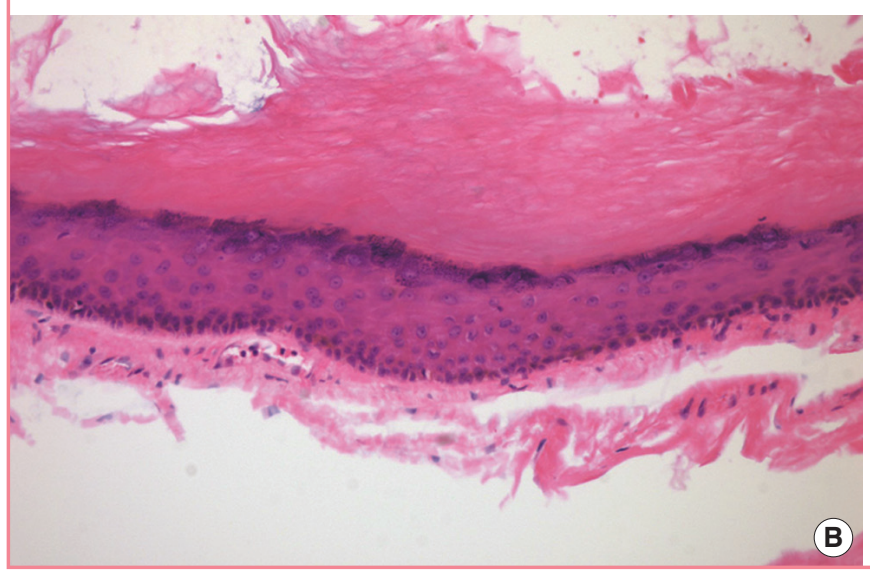

Lorenzo, Puerto Rico) was applied after suture closure, and this plays a key role in making the wound waterproof and providing a protective film.

\section{RESULTS}

We treated 10 male and 7 female patients having a mean age of 60.1 years (range, 38-78 years). Fifteen of these patients had associated diseases including diabetes, rheumatoid arthritis, and chronic renal failure. The duration of disease ranged from 1.5 to 23.5 years (mean, 9.1 years). Twelve patients had previous management histories including solid material injection, steroid injection, and simple excision. Details of the patients are given in Table 1.

All 19 PBIFs survived during follow-up (range, 6-18 months). There were three complications related to the flap procedures. One flap became partially necrotized in a patient who often lay supine to the site of the flap, causing its compression. After debridement, a vacuum-assisted wound closure system (VAC, San Antonio, TX, USA) was applied. Another PBIF was designed adjacent to the superior border of the defect and used for covering the defect. Further, partial wound dehiscence occurred in

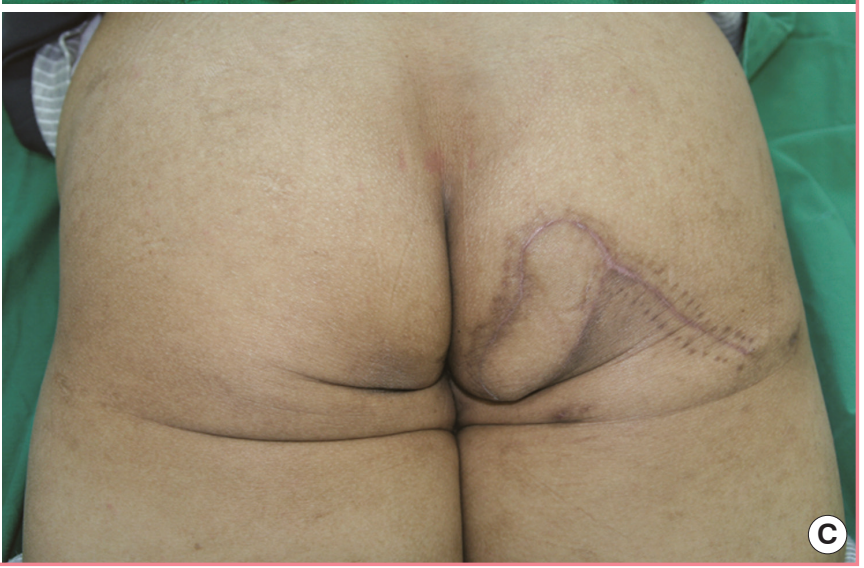

two patients, and wound revision was carried out in these cases.

\section{Cases 3 and 4}

A 50-year-old female was referred to our department for two masses on her coccyx and right ischium, respectively, which had enlarged progressively over the previous 20 years (Fig. 2A, B). She had been admitted to the department of rheumatology to control her rheumatoid arthritis. Her history included an injection of a sclerosing agent to the coccygeal area when she was young, but the ischial region had not been injected. She was prepared for surgery under general anesthesia, and her masses were removed in the operating room.

The bigger mass on her coccyx was removed, and a PBIF 15 $\mathrm{cm} \times 6 \mathrm{~cm}$ was elevated from beside the post-excisional defect to cover it. The mass on the right ischial region was removed and covered with another PBIF, $7 \mathrm{~cm} \times 3 \mathrm{~cm}$ in size (Fig. 2C, D). On pathological examination, both masses were shown to be epidermal inclusion cysts (Fig. 2E).

The patient was non-compliant after the surgery and did not position herself in the prone position as recommended, but often lay in a supine position. After 7 days, the distal portion of the flap on the coccyx had become necrotized and was debrided under 
local anesthesia. A subatmospheric pressure dressing was used to cover the defect.

Two weeks later, the wound was clean and well vascularized. A small PBIF $4 \mathrm{~cm} \times 5 \mathrm{~cm}$ in size was designed and elevated to cover the defect. The flap survived completely, and there have been no other complications over an 8-month period (Fig. 2F).

\section{Case 10}

A 77-year-old diabetic male visited our outpatient clinic complaining of a mass on the right ischium that had been growing for 11 years. Two years previously, he had undergone incisional drainage of the cyst at a local clinic, but after a year, the cyst had recurred and had grown even bigger. He was admitted for surgery, and the mass was removed under general anesthesia (Fig. 3A, B). The defect measured $2.5 \mathrm{~cm} \times 4 \mathrm{~cm}$ at its outer surface with a 6-cm internal pocket. The defect was sufficiently small for primary closure, but there was a considerable amount of dead space resulting from the excision of the mass. To fill this dead space, a perforator near the defect was identified, and a PBIF $9 \mathrm{~cm} \times 4 \mathrm{~cm}$ in size was elevated from the buttock and used to cover the defect. First, the pivot point was closed; then, the remaining donor site was closed; and thereafter, the partially de-epithelized flap was inset to obliterate the dead space. Negative suction drainages were positioned at the donor site, and Dermabond (Ethicon) was applied to the flap to save it from contamination by fecal material. The patient was followed up for 9 more months, and there were no complications or recurrences (Fig. 3C).

\section{DISCUSSION}

Most reports on the treatment of epidermal cysts thus far have focused on minimally invasive treatments in terms of reducing scars and finding simpler surgical methods for removing small epidermal cysts [4-7]. These reports involved the use of laser modalities and various incision techniques for removing the cysts, such as punch incisions and elliptical linear incisions [5-7]. There have been few publications about relatively large epidermal cysts, and most of these are either reports of the diagnosis of such cysts using radiologic modalities or sporadic case reports [1-3]. However, little attention has been paid to the treatment of large epidermal cysts, particularly infected cases, and there are no large-scale studies on this topic. Irrespective of treatment modalities, most authors have accepted that complete excision, including the whole sac, is essential to avoid recurrence $[5,6]$. It follows that large infected epidermal cysts must be removed surgically along with the surrounding infected tissues, since there is considerable adhesion and portions of the cyst walls tend to be ruptured.
Most of our patients were suffering from various underlying medical diseases including rheumatic arthritis and diabetes mellitus. As they were suffering from a chronic disease and had persistent pain, the patients overlooked the presence of small epidermal cysts; this resulted in further growth of the cysts, which then became infected. Moreover, adjunctive procedures such as incision and drainage, although reported in some articles to be useful in reducing the size of cysts $[7,8]$, were found to increase the risk of infection and make the cysts grow even larger. Hence, we think that large epidermal cysts, particularly in patients with underlying medical diseases, should be removed and reconstructed in a single surgical procedure rather than only being removed after drainage. Further, because of the underlying diseases, primary closure with a considerable amount of tension and dead space increased the risk of delayed wound healing. Hence, to cover large defects and obliterate dead space after the removal of large infected epidermal cysts on the buttocks, flap coverage was often required.

Numerous flaps have been reported in the buttocks: V-Y advancement flaps $[9,10]$, gluteus maximus myocutaneous flaps [11], adipofascial turnover flaps [12], and recently, superior gluteal artery perforator flaps [13]. However, larger defects require greater recruitment of local tissue for coverage using $\mathrm{V}-\mathrm{Y}$ rotation and advancement flaps.

Some authors have advocated the use of V-Y advancement flaps because these flaps require less dissection and mobilization of tissues and lead to a lower incidence of seromas and hematoma $[9,10]$. Sungur et al. [10] employed modifications of V-Y rotation and advancement flaps for various sizes of pilonidal sinus defects. The short skin incisions and large skin bridges reduced the risk of fecal contamination and resulted in shorter operative times. These flaps are simple and useful for moderate defects of the buttock. However, for coverage of extensive defects, bilateral $\mathrm{V}-\mathrm{Y}$ advancement flaps are necessary, and this can prolong the operative time. There is also some concern regarding the vascularity of these flaps, since these flaps are random pattern flaps and are not based on an axial artery. Hence, reconstruction of extensive defects using V-Y advancement flaps remains a challenge $[13,14]$.

As the buttocks have numerous perforators, Koshima et al. [15] pioneered the use of perforator flaps for coverage of sacral sores, and since then, many studies have reported the use of perforator flaps to cover pressure sores. These perforator flaps allow versatile flap design, and it is possible to harvest large flaps with minimal donor morbidity. However, the procedure requires meticulous transmuscular dissection of the perforator pedicle.

In our flap design, we leave a bulk of soft tissue around the pedicle and take care not to fully skeletonize it, in order to pre- 
vent vessel spasm and twisting. According to Koshima et al. [15] anatomical study, there are numerous invisible "microperforators" from the lumbar, sacral, and gluteal arteries in the buttocks, and the undissected proximal portions of flaps are thought to include numerous such microperforators, which thus enhance the vascularity of the flap. Further, the total operative time is reduced because microdissection of the pedicles is not required. When we surveyed our previous experience of the application of these PBIFs to various defects, we noted no instances of flap loss [16,17].

The most advantageous aspect of this flap is that its composition can be tailored to the defect. The flap can be modified to include a large bulk of fat tissue by beveled elevation of its distal border. If only a small region of the defect is deep, one can include a small portion of muscle, just as much as is necessary to fill the deep portion. If only soft tissue is required to obliterate the dead space, a de-epithelialized flap can be used; the flap must be slightly larger than the defect, because one can always modify the flap to fit the defect and obliterate the dead space.

In our experience, some skill is needed to successfully transpose the flap without fully isolating the pedicle. When the rotation of the flap into the defect is insufficient, the incision is extended to the proximal border of the flap around the pedicles. Then, dissection to the suprafascial layer is performed, and the flap is undermined, taking care to avoid injury to the perforator. With this technique, a more natural rotation of the flap is possible, which prevents the dog-ear deformities that are sometimes observed in the case of conventional musculocutaneous flaps. It also allows tension-free closure between the rotated flap and the donor site (T-junction), which is important for the survival of the entire flap.

The PBIF has many advantages including freedom of location and size, and minimal sacrifice of muscle. As shown in cases 3 and 4, one can harvest as many flaps as needed according to perforator location. Further, the PBIF procedure is simpler and faster than true perforator flap techniques that require dissection around the perforator pedicle, with less spasm and twisting of the pedicles due to the surrounding soft tissue bulk.

For large epidermal cysts, particularly in patients with underlying medical diseases, immediate reconstruction after removal is mandatory. Further, because of the underlying diseases and medications, primary closure with tension and dead space increases the risk of delayed wound healing. Therefore, the PBIF is well-suited to cover the large defects and obliterate dead space after the removal of large infected epidermal cysts, which can reduce the duration of treatment.

\section{REFERENCES}

1. Takemura N, Fujii N, Shibata C, et al. Fluid-fluid level in a giant epidermal cyst of the buttock.J Dermatol 2007;34:193-7.

2. Yamamoto T, Nishikawa T, Fujii T, et al. A giant epidermoid cyst demonstrated by magnetic resonance imaging. $\mathrm{Br} \mathrm{J}$ Dermatol 2001;144:217-8.

3. Golshan Momeni M, Anavim A, Lin F, et al. Giant epidermal inclusion cyst of buttock. Skeletal Radiol 2006;35:864-6.

4. El Alami M, Ghufoor K, Dilkes M. Laser marsipulization of epidermal cysts: avoiding linear scars. J Clin Laser Med Surg 2003;21:161-3.

5. Funayama E, Oyama A, Furukawa H, et al. A new modified technique for removing epidermal cysts using a trepan in one stage with a smaller postoperative scar and no recurrence. Dermatol Surg 2010;36:2050-2.

6. Lee HE, Yang $\mathrm{CH}$, Chen $\mathrm{CH}$, et al. Comparison of the surgical outcomes of punch incision and elliptical excision in treating epidermal inclusion cysts: a prospective, randomized study. Dermatol Surg 2006;32:520-5.

7. Wu H, Wang $\mathrm{S}, \mathrm{Wu} \mathrm{L}$, et al. A new procedure for treating a sebaceous cyst: removal of the cyst content with a laser punch and the cyst wall with a minimal postponed excision. Aesthetic Plast Surg 2009;33:597-9.

8. Nakamura M. Treating a sebaceous cyst: an incisional technique. Aesthetic Plast Surg 2001;25:52-6.

9. Schoeller T, Wechselberger G, Otto A, et al. Definite surgical treatment of complicated recurrent pilonidal disease with a modified fasciocutaneous V-Y advancement flap. Surgery 1997;121:258-63.

10. Sungur N, Kocer U, Uysal A, et al. V-Y rotation advancement fasciocutaneous flap for excisional defects of pilonidal sinus. Plast Reconstr Surg 2006;117:2448-54.

11. Rosen W, Davidson JS. Gluteus maximus musculocutaneous flap for the treatment of recalcitrant pilonidal disease. Ann Plast Surg 1996;37:293-7.

12. Onishi K, Maruyama Y. Sacral adipofascial turn-over flap for the excisional defect of pilonidal sinus. Plast Reconstr Surg 2001;108:2006-10.

13. Basterzi Y, Canbaz H, Aksoy A, et al. Reconstruction of extensive pilonidal sinus defects with the use of S-GAP flaps. Ann Plast Surg 2008;61:197-200.

14. Lee SR, Kim DA, Oh SH. Reconstruction of the recurrent ischial sore with modified gluteus maximus myocutaneous V-Y advancement flap. J Korean Soc Plast Reconstr Surg 2009; 36:714-9.

15. Koshima I, Moriguchi T, Soeda S, et al. The gluteal perforator-based flap for repair of sacral pressure sores. Plast Recon- 
str Surg 1993;91:678-83.

16. Kim YH, Naidu S, Kim CY, et al. A perforator solution for excisional defects of pilonidal sinus. J Plast Reconstr Aesthet Surg 2011;64:138-40.
17. Kim JT, Kim YH, Naidu S. Perfecting the design of the gluteus maximus perforator-based island flap for coverage of buttock defects. Plast Reconstr Surg 2010;125:1744-51. 